\title{
A New Production Splitting Method Based On Discrimination Of Injection- Production Relation
}

\author{
Baorong Deng*, Jiqun Zhang, Junhua Chang, Xinhao Li, Hua Li, and Xianing Li, Research \\ Institute of Petroleum Exploration \& Development, PetroChina, Beijing, China
}

\begin{abstract}
The complex mature oilfields in China have been operated for a long history. During their exploration and development, a large amount of diverse production and research data with complicated formats were generated. The gradual penetration of geology research requires more precise reservoir analysis and research. Accordingly, it is urgent to make reservoir performance fine analysis for these mature oilfields using efficient and innovative data processing technologies. In this paper, multi-layer water flooding reservoirs were discussed with multi-disciplinary data. Through automatic discrimination of injectionproduction relation by computer, vertical and horizontal water flow rates were analyzed quantitatively to diagnose the directions and layers of dominant water flow. Then, the productions of production well and water injection well were split by layers to clarify how the water injection affects the performance of production well. Compared with conventional methods, the proposed new method is more comprehensive and reasonable in application of data and more scientific and accurate in reservoir performance fine analysis. The software developed on this method has been applied in hundreds of reservoir blocks in Daqing, Jidong, Jilin, Liaohe, Xinjiang and other oilfields. It is of significant guidance for evaluation on remaining oil potential and preparation of development adjustment plan for mature oil-fields.
\end{abstract}

\section{Introduction}

The production splitting method is critical for the reservoir engineers to figure out the layered injectionproduction amount of each vertical layer of the single well, and it has long been paid attention by the professionals. Various splitting methods include early $\mathrm{KH}$ value splitting method, numerical simulation method ( $\mathrm{Li}$ et al. 2011), monitoring data restraining method ( $\mathrm{Li}$ et al. 2010), improved formation coefficient method (Cao et al. 2014; Lan et al. 2012) and so on. However, the production splitting method taking the production well and water injection well as a unified whole and considering multiple layers, multiple directions, artificial intervention and multiple constraints based on the discrimination of injection-production relation has not been reported.

By applying various geological, dynamic, monitoring and technological data of the mature oilfields and combining with reservoir experts' experience, geological achievement, dynamic/static behaviors and monitoring data, the reservoir performance fine analysis method in the use of computer technology was studied in this paper. Automatic discrimination of injection-production relation in the single sand body unit by the innovative application of computational geometry discipline was conducted to analyze and evaluate how the well pattern controls the sand body. And then, the well group and layer in which the injected water had an inefficient circulation were found out. Based on the discrimination of injectionproduction relation, injection-production flow resistance calculation and water injection rate splitting, this paper presented an innovative production well production splitting technology with multiple constraints and compiled the software system. Thus, a reliable research method is provided for clarifying the main

Copyright $(C$ the author(s). This work is licensed under a Creative Commons Attribution 4.0 International License.

DOI: $10.14800 /$ IOGR.437

Received July 1, 2019; revised August 11, 2019; accepted August 23, 2019.

*Corresponding author: dbr@petrochina.com.cn 
water production horizon and separate layer oil production of the production well, evaluating the vertical layered production of reserves more scientifically and studying the remaining oil potential distribution.

\section{Water Injection Rate Splitting Technology}

Injection-production relation is the foundation to discuss the water flooding direction, water flow rate, water injection rate and oil production effect. With the gradual penetration of geology research, after the sedimentary micro-facies are subdivided, single sand bodies partly uncontrolled appear in the oil reservoir that was considered being controlled by the well pattern. Especially, as to the complex fault block reservoirs, many faults, discontinuous sand bodies and frequent development adjustment measures such as re-perforation or altering layers have made the artificial analysis of injection-production relation over the past years more difficult.

Intelligent discrimination of injection-production relation by computers is conducted according to the following principles.

1) Production wells and water injection wells distributed in different sand bodies are disconnected.

2) Water injection wells or production wells drilled in the mudstone area are disconnected.

3) The closed faults or mudstone area occlusions are disconnected.

4) Too long water flow path and immobile or weak mobile water flow are caused by sand-body forms.

5) The flow may steer clear of obstacles under suitable conditions.

6) The indirect production wells in line are difficult to connect.

7) Two water injection wells on one side of the production well on the same straight line are difficult to be injected.

8) The suitable well spacing and well pattern in the same sand body have flow connections.

9) Production wells may connect in multiple directions.

10) A water injection well may connect many production wells under the condition of the proper angle and well spacing.

11) Water injection wells and production wells not perforated simultaneously are not corresponding.

12) The flow line cannot cross.

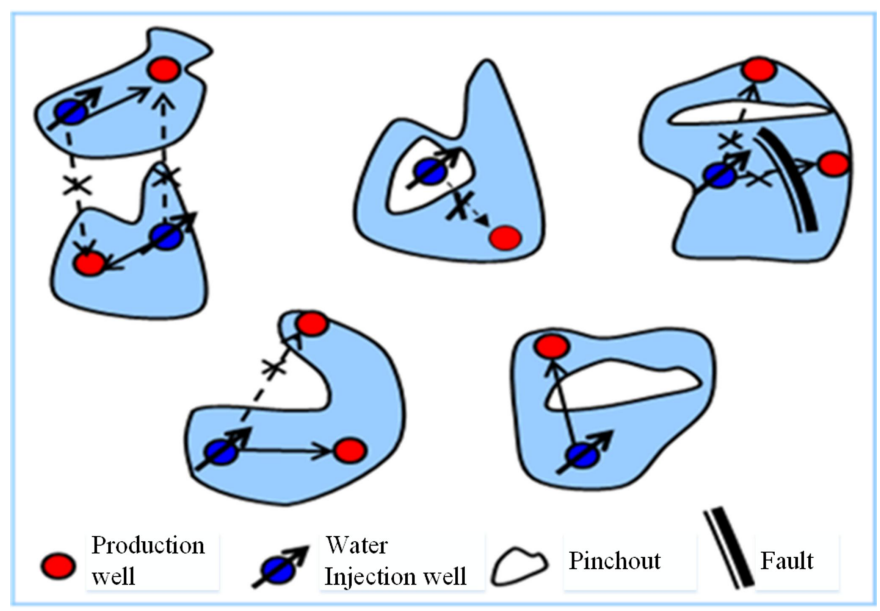

Figure 1-Injection-production relations influenced by single sand body forms, pinchout and faults. 


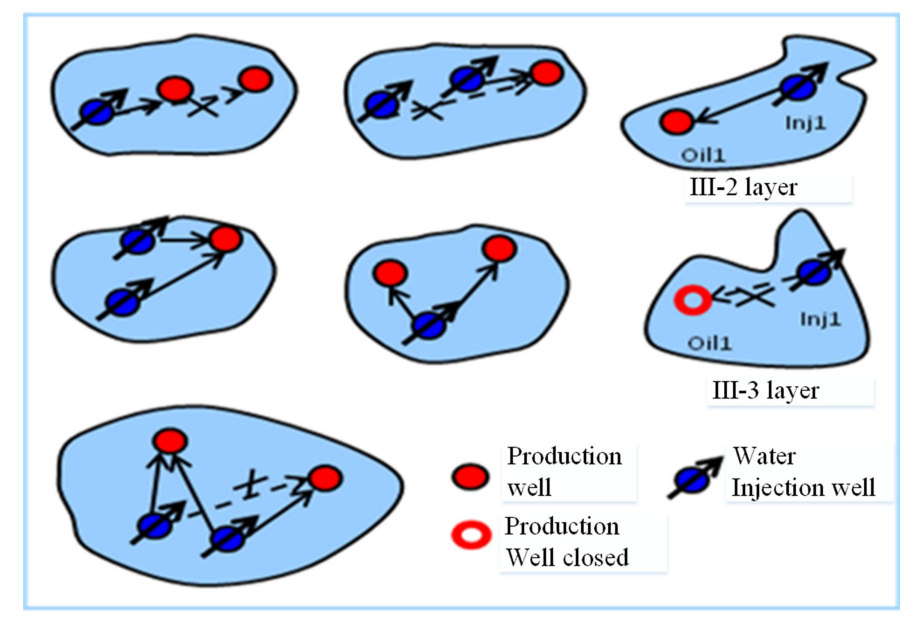

Figure 2-Injection-production relations influenced by well pattern, such as indirect connections and pressure conduction.

As shown in Figures 1 and 2. It is necessary to determine the injection-production pathway, that is, to discriminate the least resistance path between water injection well and production well.

\section{Discrimination Method of the Least Resistance Path between Water Injection Well and Production well}

By comprehensively applying the data about the reservoir physical property, single sand body spread and forms, fault geometry and sealing capacity, production performance data, water absorption and liquid production profile, perforation and stimulation horizons in oil production and water injection wells, the relative position of the oil and water injection wells and tracer monitoring, the data error was automatically discriminated and the compatibility analysis was made for various information. The least resistance path between water injection well and production well was calculated by applying computational geometry and graphics. The procedures are as follows:

1) The data of static physical properties of geological models such as permeability and thickness field was imported.

2) The visibility graph was constructed.

3) The weighted visibility graph was built according to the static parameter field data describing the characteristics of the reservoir direction.

4) The least resistance path between injection and production wells was calculated by applying the Dijkstra algorithm.

Computational geometry was applied in the visibility graph construction. Considering the morphology of non-flow areas such as sand body, fault and mudstone, on the basis of static data field for geological modeling, the center point of each grid was regarded as the vertex in the visibility graph, namely visible point, visible to the four center points (above, below, left and right) at most. If there is a closed fault between the adjacent grids or one of them is located in the non-flow area, it is invisible. According to the above principles, the visibility graph construction of all the visible points is shown in Figure 3. Its algorithm is described below.

A free space $C_{\text {free }}$ is defined, which is composed of two simple disjoint polygons. One polygon is outer boundary, and the other one is inner boundary, namely obstacle, as shown in Figure 3a. Both outer and inner boundaries of $\mathrm{C}_{\text {free }}$ are open sets, and the tangency between microarrayer and outer/inner boundary is acceptable. A starting location A (the location of water injection well (Inj) in blue circle) and a termination location B (the location of production well (Oil) in red circle) are given, which both belong to $C_{\text {free. }}$

Construction algorithm for the visibility graph $G_{\text {vis }}\left(C_{\text {free }}\right)$ of $C_{\text {free }}$ and Points A and B:

Algorithm: VisiblithGraph $\left(C_{\text {free}}, \mathrm{A}, \mathrm{B}\right)$

Inputs: the inner and outer boundaries of the free space $C_{\text {free, }}$ and the two points (A and B) within the $C_{\text {free. }}$

Outputs: visibility graph $G_{\text {vis }}\left(C_{\text {free }}, \mathrm{A}, \mathrm{B}\right)$ 
1) Initialize the graph $G_{\text {vis }}\left(C_{\text {free }}\right)=(\mathrm{V}, \mathrm{E})$ to make the set $\mathrm{V}$ include the vertexes of both inner and outer boundaries, and Points $\mathrm{A}$ and $\mathrm{B}, \mathrm{E}=\Phi$;

2) for each vertex v $\in \mathrm{V}$, do $\left.\mathrm{W} \leftarrow \operatorname{VisiblityVertices~(v,~} C_{\text {free }}\right)$;

3) for each vertex $w \in W$, add the $\operatorname{arc}(v, w)$ into $E$;

4) return $G_{\text {vis }}\left(C_{\text {free, }}\right.$ A, B).

The rotary plane sweep method (Mark el al. 2007) was applied in the subprocess of Visiblity Vertices. Its inputs include a group of polygons within the $C_{\text {free }}$ and a point $\mathrm{v}$ on the plane. All the vertexes visible to v are found out from the vertexes of inner and outer boundaries of the $C_{\text {free. }}$.

From the construction algorithm of the visibility graph in Figure $3 \mathrm{a}$, the visibility graph $G_{\text {vis }}\left(C_{\text {free }}, \mathrm{A}, \mathrm{B}\right)$ is obtained, as shown in Figure 3b.

The base map of Figure $3 b$ is the KH field data sketch map, describing the characteristics of the reservoir direction. Water injected flows along the direction with the highest permeability, biggest thickness and pressure difference. Based on the visibility graph constructed, the pseudo-resistance among the grids is calculated according to the parameters such as grid permeability and thickness. Finally, the shortest path from A to B is calculated by the Dijkstra algorithm (Reinhard 2013), as shown in Figure 3c.

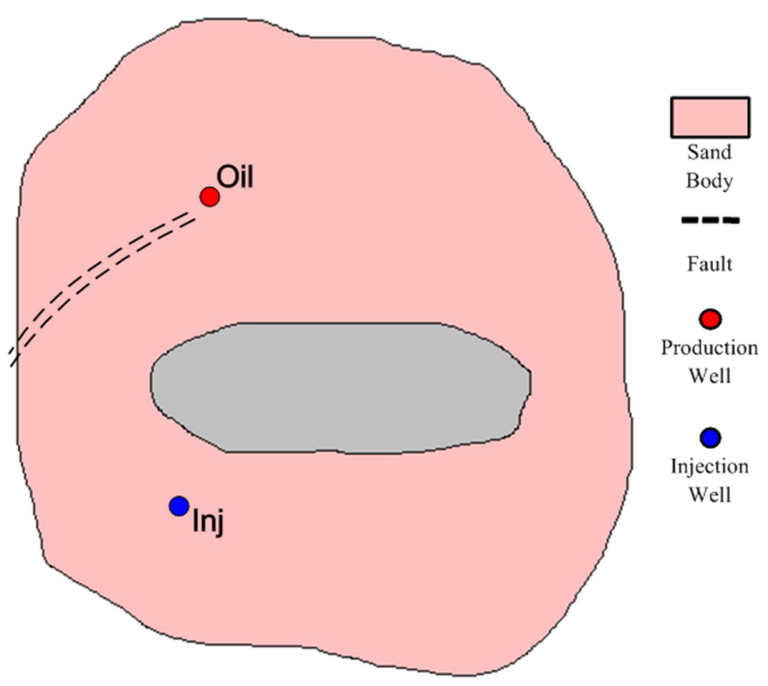

(a)

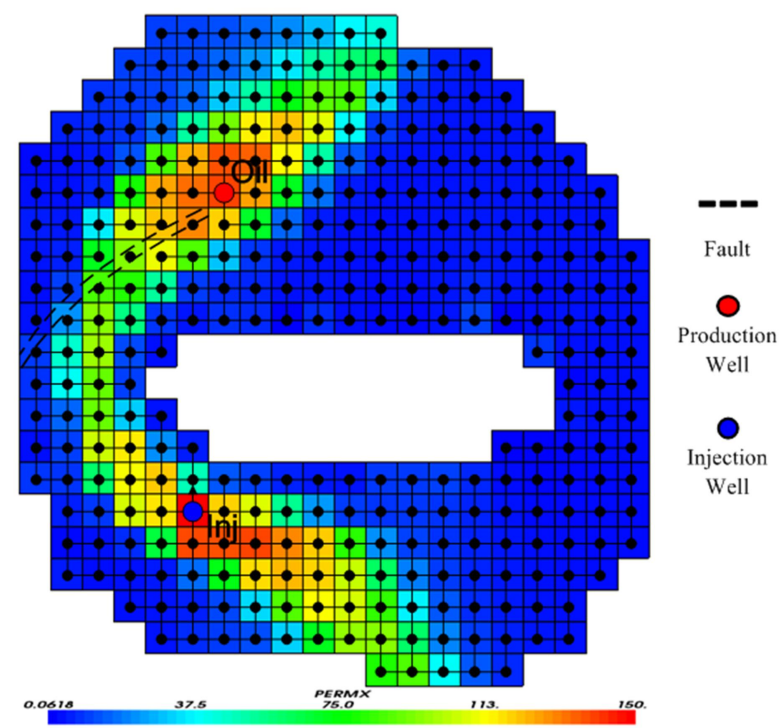

(b) 


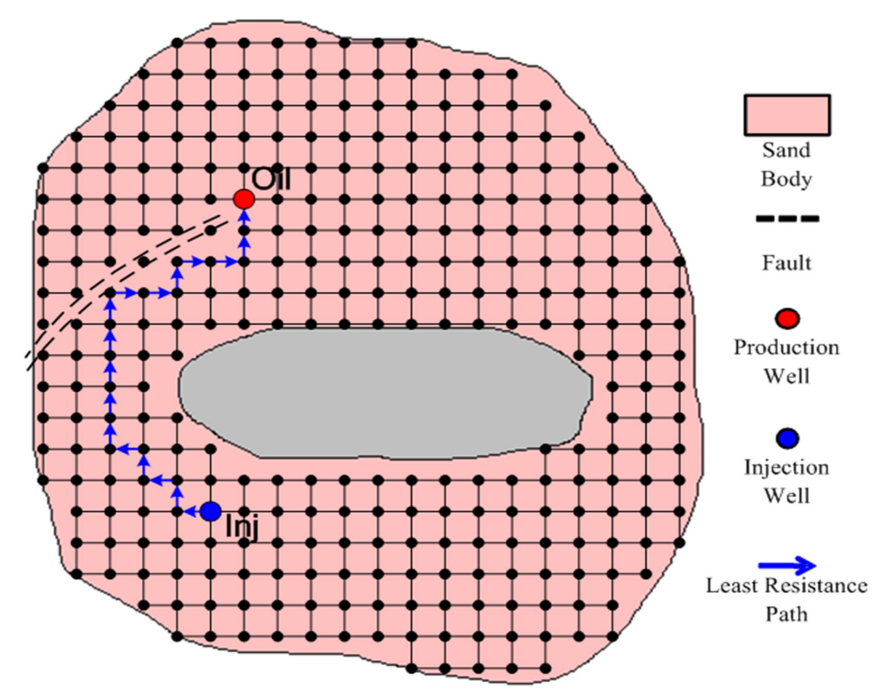

(c)

Figure 3-Construction of all the visible points. (a) The sand body where water injection well (Inj) and production well (Oi)l are located. (b) The unweighted visibility graph of the sand body. (c) The least resistance path between water injection well (Inj) and production well (Oil).

Discrimination Method for Indirect Connection Wells. The discrimination method for indirect connection wells is complicated. Once the direct connections are discriminated depending on the reservoir development characteristics, well pattern distribution mode and injection-production pressure difference, the indirect connections are considered existing if the distance between the indirect connection well and direct connection well and the downhole pressure are both small enough and the permeability and thickness are both big enough, that is, the resistance is below a certain threshold value. The threshold value can be determined according to the liquid volume and pressure of the indirect connection wells.

In this paper, by applying geometrical morphology, the indirect connections are discriminated under the constraint of static and dynamic data, as shown in Figure 4. To discriminate whether the well $\mathrm{O}$ is indirect connection, it is necessary to discriminate whether the wells $\mathrm{B}, \mathrm{D}$ or $\mathrm{C}$ are interfering wells. Taking the well $\mathrm{B}$ as example, if $\angle \mathrm{BWO}$ and $\angle \mathrm{BOW}$ are respectively less than a certain threshold value, the well $\mathrm{B}$ is indirect connection.

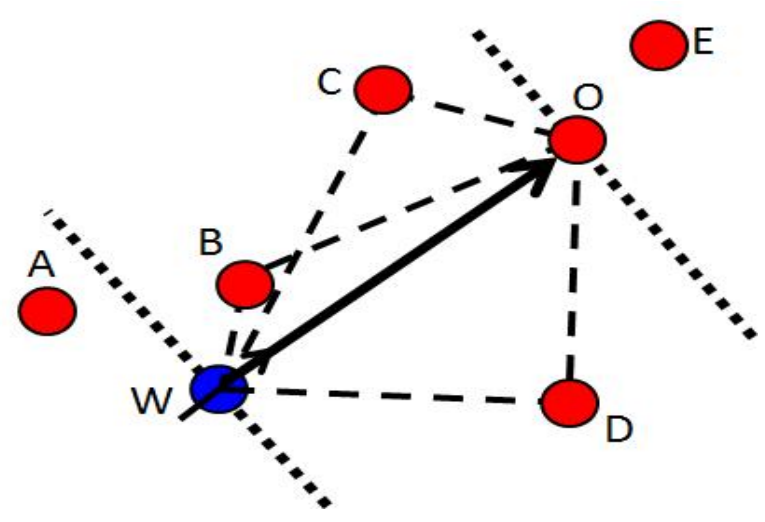

Figure 4-Indirect injection-production connections discrimination. 


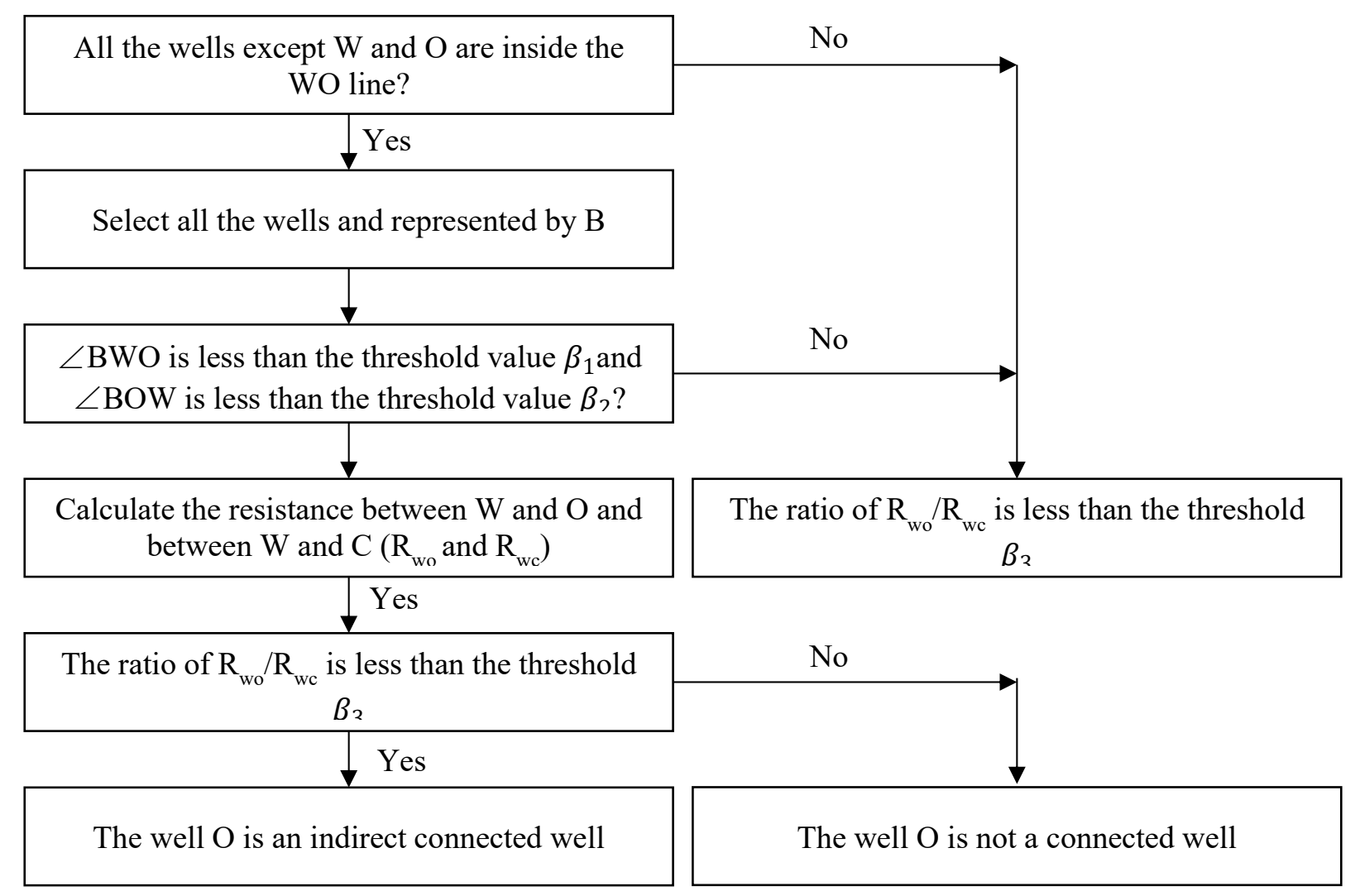

Figure 5-The discrimination flow of indirect connections.

After indirect connections are discriminated, the resistance $\mathrm{R}_{\mathrm{WO}}$ between the wells $\mathrm{W}$ and $\mathrm{O}$ and the resistance $R_{W B}$ between the wells $\mathrm{W}$ and $\mathrm{B}$ are calculated by applying the permeability between production well and water injection well, reservoir thick-ness, injection-production pressure difference and others. If the value of $\mathrm{R}_{\mathrm{WO}} / \mathrm{R}_{\mathrm{WB}}$ is below a certain threshold value, the well $\mathrm{O}$ is indirect connection. The specific discrimination flow is shown in Figure 5.

\section{Dominant Water Flow Discrimination Technology}

Calculation of Plane Percolation Resistance between Water Injection Well and Production Well. By applying the layer data, well location, well trajectory, perforating data, well pattern distribution and treatments of water injection/production wells, the plane percolation resistance between water injection well and production well in a single layer (Figure 6), the percolation resistance in injection-production connections in multiple directions in multiple layers (Figure 7) and the flow of oil and water between two grids (Figure 8) are calculated according to injection-production connections, mechanics of fluids flow and principle of hydroelectricity similarity.

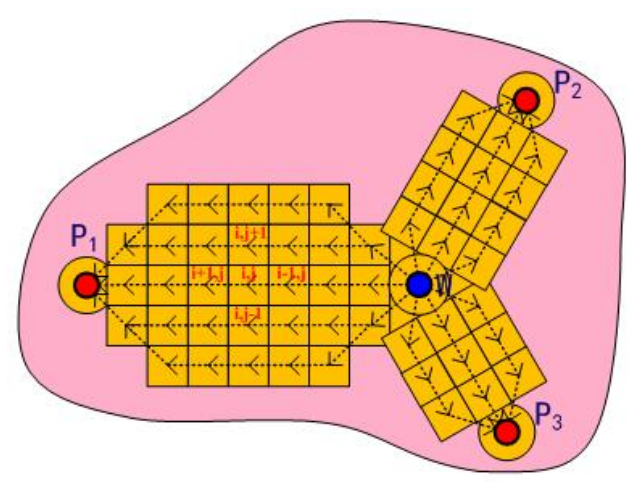

Figure 6-Plane percolation resistance between water injection well and production well in a single layer. 


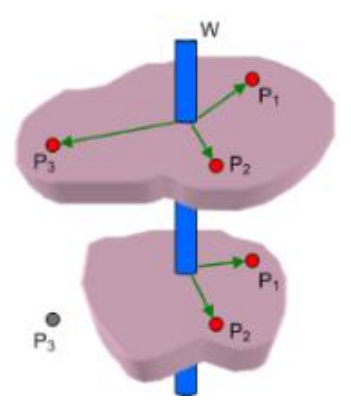

Figure 7-The percolation resistance in injection-production connections in multiple directions in multiple. layers

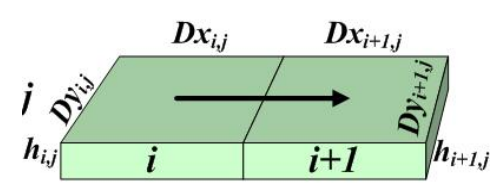

Figure 8-The flow of oil and water between two grids.

The total resistance between the $\mathrm{w}^{\text {th }}$ water injection well and the surrounding connected production wells is as follows,

$$
\bar{\Omega}_{w}=\frac{1}{\sum_{Z=1}^{v} \frac{1}{\Omega_{w, Z}}}
$$

The resistance between the $\mathrm{w}^{\text {th }}$ water injection well and the surrounding connected production wells in the $\mathrm{z}^{\text {th }}$ layer is as follows,

$$
\Omega_{w, z}=\frac{1}{\sum_{p=1}^{S} \frac{1}{\Omega_{w, p, z}}}
$$

The resistance between the $\mathrm{w}^{\text {th }}$ water injection well and the $\mathrm{p}^{\text {th }}$ production well in the $\mathrm{z}^{\text {th }}$ layer is as follows,

$$
\Omega_{w, p, z}=\frac{\mu_{w}}{2 \pi K_{w, z} h_{w, z}} \ln \left(\frac{r_{e}}{r}\right)+\Omega_{\text {outer }}+\frac{\mu_{o}}{2 \pi K_{p, z} h_{p, z}} \ln \left(\frac{r_{e}}{r}\right) \ldots
$$

The external resistance between the $\mathrm{w}^{\text {th }}$ water injection well and the $\mathrm{p}^{\text {th }}$ production well in the $\mathrm{z}^{\text {th }}$ layer is as follows,

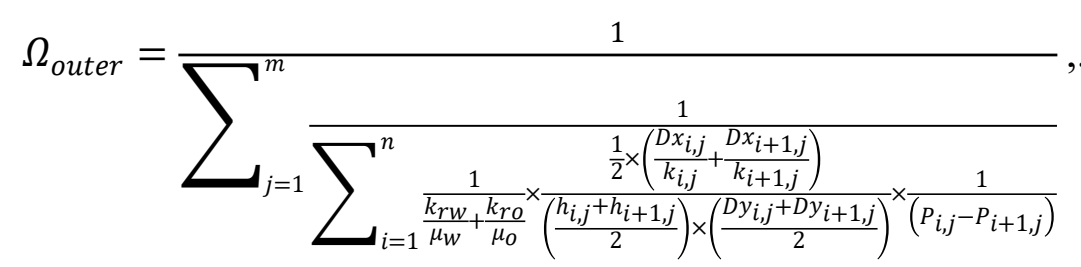

where, $\mathrm{w}$ is the number of water injection well; $\mathrm{z}$ is the layer number; $\mathrm{v}$ is the layer amount; $\mathrm{p}$ is the number of production well connected with water injection well in the $\mathrm{z}^{\text {th }}$ layer; $\mathrm{s}$ is the total number of production wells connected with water injection well in the $\mathrm{x}^{\text {th }}$ layer; $\mu_{\mathrm{w}}$ is water viscosity, $\mathrm{mPa} . \mathrm{s} ; \mu_{\mathrm{o}}$ is oil viscosity, $m P a . s ; K_{w, z}$ is the permeability of the $\mathrm{w}^{\text {th }}$ water injection well in the $\mathrm{z}^{\text {th }}$ layer, $\mathrm{mD} ; \mathrm{h}_{\mathrm{w}, \mathrm{z}}$ is the effective thickness of $\mathrm{w}^{\text {th }}$ water injection well in the $\mathrm{z}^{\text {th }}$ layer, $\mathrm{m} ; \mathrm{r}_{\mathrm{e}}$ is the outer boundary of the radial flow, $m$; $r$ is the well radius, $m ; K_{p, z}$ is the permeability of the $p^{\text {th }}$ production well in the $z^{\text {th }}$ layer, $m$; $h_{p, z}$ is the effective thickness of the $\mathrm{p}^{\text {th }}$ production well in the $\mathrm{z}^{\text {th }}$ layer, $\mathrm{m} ; \mathrm{m}$ is the number of simulative grids in the vertical direction of water flow; $n$ is the number of simulative grids from the water injection well to production well; $\mathrm{K}_{\mathrm{rw}}$ is the elative permeability of water phase; $\mathrm{K}_{\mathrm{ro}}$ is the relative permeability of oil phase; $D x_{i, j}$ is the width in the $X$ direction of the grid in the $i^{\text {th }}$ row and the $j^{\text {th }}$ column, $m ; k_{i, j}$ is the permeability of the grid in the $\mathrm{i}^{\text {th }}$ row and the $\mathrm{j}^{\text {th }}$ column, $\mathrm{mD}$; $\mathrm{h}_{\mathrm{i}, \mathrm{j}}$ is the thickness of the grid in the $\mathrm{i}^{\text {th }}$ row 
and the $\mathrm{j}^{\text {th }}$ column, $\mathrm{m}$; $D \mathrm{y}_{\mathrm{i}, \mathrm{j}}$ is the width in the $\mathrm{Y}$ direction of the grid in the $\mathrm{i}^{\text {th }}$ row and the $\mathrm{j}^{\text {th }}$ column, $\mathrm{m}$; $\mathrm{p}_{\mathrm{i}, \mathrm{j}}$ is the pressure of the grid in the $\mathrm{i}^{\text {th }}$ row and the $\mathrm{j}^{\text {th }}$ column, $\mathrm{MPa}$.

Calculation of Water Injection Flow Rate Considering Treatment and Monitoring Data. Under the constraints of water adsorption profile, layered pressure drop testing data, well logging data in the waterflooded layer and plane comprehensive resistance coefficient, the vertical splitting coefficient is calculated.

The relative flow rate of an injection-production unit in the single sand body is as follows,

$$
Q_{w, p, z}=\beta \times \frac{\Delta P}{\Omega_{w, p, z}}, \ldots
$$

where, $\beta$ is the constraint factor considering the treatment and monitoring data, etc; $\Delta \mathrm{P}$ is is the pressure difference between water injection well and production well.

$$
\lambda_{w, p, z}=\frac{Q_{w, p, z}}{\sum_{p=1}^{S} Q_{w, p, z}}
$$

The scale coefficient of water injection rate splitting of the $\mathrm{w}_{\text {th }}$ water injection well in each layer is as follows,

$$
\lambda_{w, z}=\frac{\sum_{p=1}^{s} Q_{w, p, z}}{\sum_{z=1}^{v} \sum_{p=1}^{s} Q_{w, p, z}}
$$

According to the scale coefficients, the water flow in each direction of each layer of injectionproduction unit can be calculated.

\section{Production Splitting Technology under the Constraint of Multiple Conditions}

On the basis of research on injection-production relation mentioned and water injection rate splitting above, this new method deals with layer water cut, with the accordance ratio of indexes of the well only to verify the model precision. The calculation of oil production in each layer is relatively complicated. Relevant technical points are given as follows:

1) The comprehensive information system is set up;

2) The injection-production flow connection in each layer is discriminated automatically by computer;

3) Water injection rate in each layer is calculated using flow resistance, layered water injection and other data;

4) The flow resistance is corrected using the pressure drop testing data in each layer, and the concept of pressure drop factor is introduced. Based on the pressure drop amplitude of water injection well in each layer in 48 hours, the splitting coefficient of water injection rate in each layer is determined and corrected;

5) Considering the rise of liquid volume in injection-production unit caused by fracturing, the injection-production flow resistance is reduced in proportion;

6) According to the principle of material balance, the liquid production profile is calculated, and thus liquid-producing capacity of production well in each layer is obtained;

7) The oilfield development rule is analyzed and the recovery percent of layer is constrained;

8) Logging data in the water-flooded zone is used to correct the layer water cut;

9) The data of inspection wells are used to correct the saturation of remaining oil and water cut in well layers;

10) According to the de-crease amplitude of water cut in the whole well or the rising amplitude of water cut in the re-perforated water layer after re-perforation, the splitting ratio of water cut and oil production is corrected;

11) With the two-phase (oil-water) percolation theory (Ge 2003), the saturation between production well and water injection well is calculated and the water cut in well layers is constrained; 
12) By the superposition of water cut and oil production in every layer calculated and in contrast with the actual water cut and oil production of the whole well, the higher the coincidence rate and the more accurate the method, the closer the calculation results to actual production.

The technology has been applied for thousands of wells in more than 40 reservoir blocks. Compared with the water cut of the whole well, more than $80 \%$ of the wells have higher fitting rate (Figure 9). In comparison with the reservoir numerical simulation results, the trend is similar, as shown in Figure 10. By contrast with the water-cut data of the liquid production profile of 88 well layers, the average error is about 3.5\% (Table 1), suggesting a high precision.
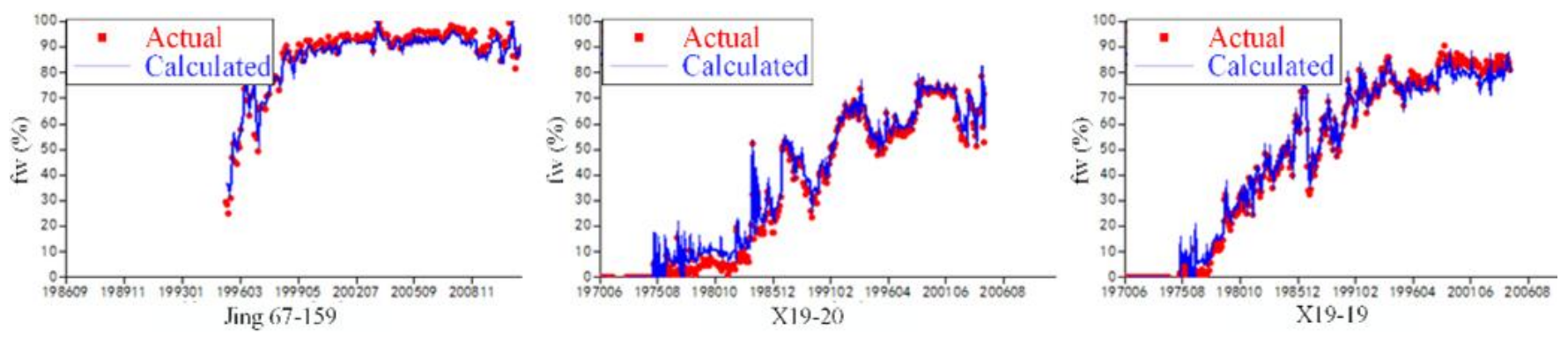

Figure 9-Comparison of calculated and designed water cut of wells.

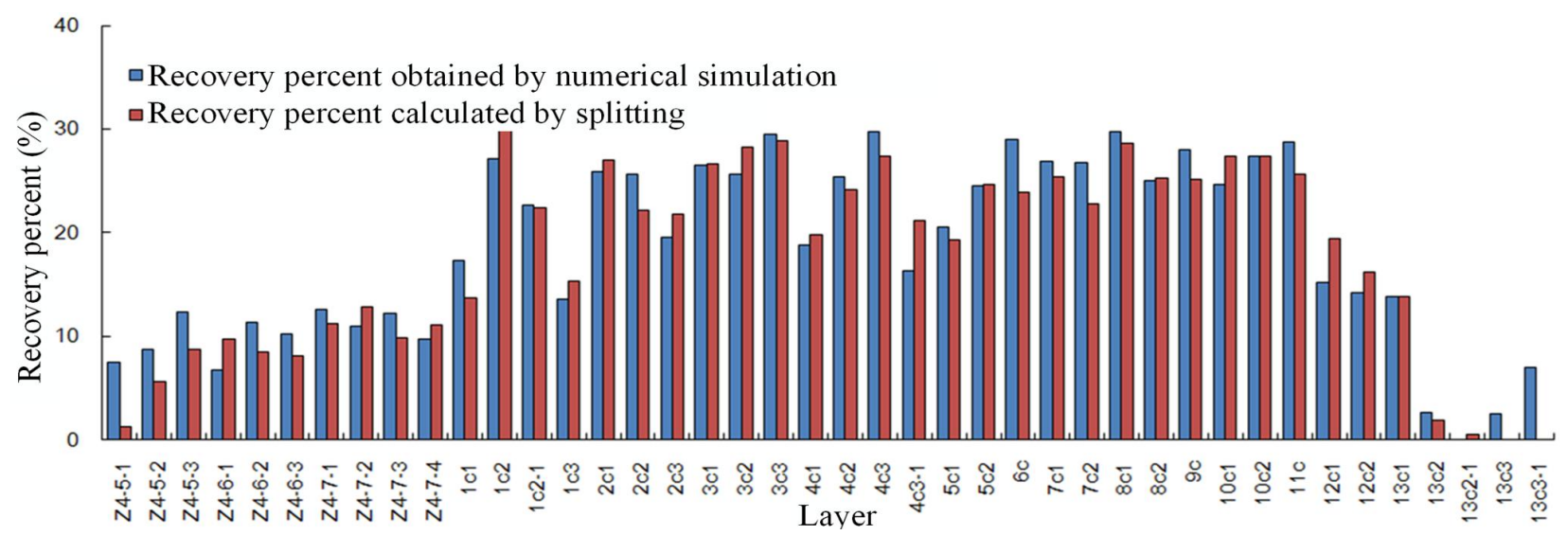

Figure 10-Recovery of layers calculated by the model and obtained by numerical simulation.

Table 1-Comparison of water cut of layers calculated by the model and production profile.

\begin{tabular}{c|c|c|c|c|c|c}
\hline $\begin{array}{c}\text { Error } \\
\text { Intervals }\end{array}$ & $\leq 1 \%$ & $1 \sim 2 \%$ & $2 \sim 4 \%$ & $4 \sim 10 \%$ & $>10 \%$ & Total \\
\hline $\begin{array}{c}\text { Layer } \\
\text { Numbers }\end{array}$ & 16 & 12 & 29 & 30 & 1 & 88 \\
\hline $\begin{array}{c}\text { Percentage } \\
\text { Accumulative } \\
\text { Percentage }\end{array}$ & 18.2 & 13.6 & 33 & 34 & 1.1 & 100 \\
\hline
\end{tabular}

\section{Applications}

Injection and Production Corresponding Degree over the Past Years. In the Bohai Bay area, the structure of complex fault block reservoir is complicated, the sand body is discontinuous and the oil- 
bearing area is small. So, it is difficult to improve the injection-production relation of single sand body and build up the effective injection-production system. When the injection-production relation of single sand body is evaluated by considering the distribution characteristics of oil sand body, the geometry of fault block and re-perforating or altering layers, it would spend considerable time to treat the historic data for decades of years if no computer software is available. However, with this technology, together with complete data, the results can be calculated in several minutes. In the compilation of secondary development plan for a reservoir block of Dagang Oilfield, the injection-production relation was analyzed for hundreds of single sand bodies by applying the technology proposed in this paper, and the perforation corresponding relation was evaluated layer by layer and well by well. Figure 11 shows the distribution of injection-production connection ratio. Any well group with the ratio of less than $60 \%$ should be emphasized.

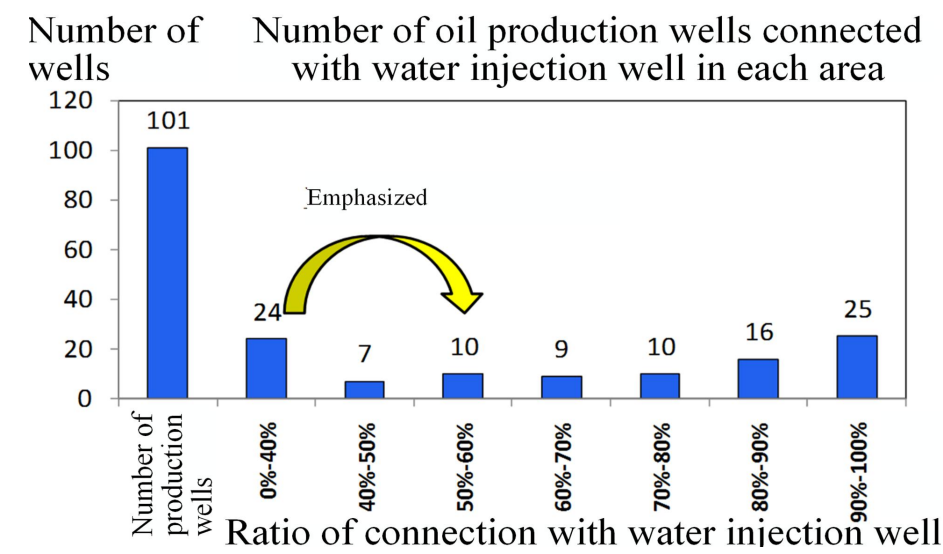

Figure 11-Distribution of production-injection connection ratio.

Production Splitting in Each Layer. The production splitting technology has been applied in thousands of wells in order to clarify the reservoir producing status in each layer and remaining reserves of single sand body. Figure 12 shows the recovery percent of 290 single sand bodies in a block of Dagang Oilfield. Specifically, 72 single sand bodies are not produced, accounting for 3.8\% of the remaining oil; 25 single sand bodies are less produced, representing a recovery percent of less than 5\%, and accounting 5.81\% of the remaining oil. So, local infill wells can be drilled depending on the vertical superposition.

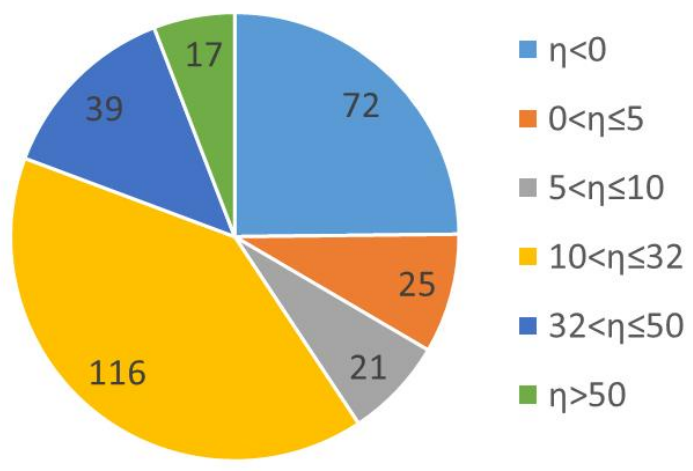

Figure 12-Recovery percent of 290 single sand bodies in a block of Dagang Oilfield.

\section{Conclusions}

By the reservoir engineers' random inspection and testing under various oil reservoir geological conditions, such as fault development in complex fault block reservoir, discontinuous sand bodies, small oil-bearing area and the reservoir with long history of production, the injection-production relation discrimination method has been proved with an accuracy over $95 \%$. 
With full consideration to static geology, production performance and treatments, the production splitting technology under constraints of multi-layer, multi-direction and multi-conditions provides the results better coincident to practical production. It is a reliable research method for quickly clarifying the producing percent of reserves in each layer and the remaining potential of single sand body.

\section{Conflicts of Interest}

The author(s) declare that they have no conflicting interests.

\section{References}

Cao, X., Zhang, F., Cai, Y., et al. 2014. Research on a New Production Split Method of Thin Interbedded Sandstone Reservoirs. Science Technology and Engineering 14(13):166-171.

Ge, J. 2003. The Modern Mechanics of Fluids Flow in Oil Reservoir. Beijing, China: Petroleum Industry Press.

Lan, L., Liu, R., Fu, Y., et al. 2012. A New Method to Cleave Production of the Separated Layers of Oil Wells. Petroleum Geology and Oilfield Development in Daqing 31(3):59-62.

Li, K., Yu, G., Wang, Q., et al. 2011. A New Production Split Method. Petroleum Geophysics 9(4):19-22.

Li, C., Liu J., Li X., et al. 2010. Principles and Application of Production Allocation for Oil and Water Injection Wells in Multilayer Commingled Development Oil Reservoir. Petroleum Geology and Oilfield Development in Daqing 29(1):55-59.

Mark, D.B., Otfried, C., Marc, V. K, et al. 2007. Computational Geometry: Algorithms and Application. Springer.

Reinhard, D. 2013. Graph Theory. Beijing, China: Higher Education Press.

Baorong Deng is a senior engineer in Research Institute of Petroleum Exploration \& Development, PetroChina. Baorong Deng specializes in production analysis, reservoir simulation and enhance oil recovery.

Jiqun Zhang is a senior engineer in Research Institute of Petroleum Exploration \& Development, PetroChina. Jiqun Zhang specializes in production analysis, reservoir simulation and enhance oil recovery.

Junhua Chang is a senior engineer in Research Institute of Petroleum Exploration \& Development, PetroChina. Junha Chang specializes in production analysis, reservoir simulation and enhance oil recovery.

Xinhao Li is a senior engineer in Research Institute of Petroleum Exploration \& Development, PetroChina. Xinhao Li specializes in production analysis, reservoir simulation and enhance oil recovery.

Hua $\mathbf{L i}$ is a senior engineer in Research Institute of Petroleum Exploration \& Development, PetroChina. Hua Li specializes in production analysis, reservoir simulation and enhance oil recovery.

Xianing Li is a senior engineer in Research Institute of Petroleum Exploration \& Development, PetroChina. Xianing Li specializes in production analysis, reservoir simulation and enhance oil recovery. 